\title{
Apertando o cinto: Síndrome de Wilkie e Síndrome de Nutcracker
}

\section{Tightening the belt: Wilkie's Syndrome and Nutcracker Syndrome}

Mulher de 61 anos, desenvolveu Síndrome do Intestino Curto após várias intervenções cirúrgicas por enterite rádica. A investigação complementar por quadro sub-oclusivo levou ao diagnóstico de Síndrome de Wilkie [compressão extrínseca da $3^{\mathrm{a}}$ porção do duodeno (DD), com dilatação a montante, por pinçamento entre a artéria mesentérica superior (AMS) e a aorta abdominal (AA) com redução do ângulo aorto-mesentérico para $<20^{\circ} \mathrm{e}$ também do Síndrome de Nutcracker [compressão da veia renal esquerda (VRE) no seu trajecto entre a aorta abdominal e artéria mesentérica superior]. 0 Síndrome de Wilkie ${ }^{\top}$ (SW) é um síndrome raro, com uma prevalência de 0,013 a 0,3\%. É secundário a alterações mecânicas e anatómicas por diminuição do panículo adiposo mesentérico (ex. estados catabólicos) ou por cirurgias que reduzam 0 ângulo aorto-mesentérico (ex. cirurgia bariátrica). Caracteriza-se por um quadro arrastado e intermitente de distensão abdominal pós-prandial, dor, náuseas, vómitos e emagrecimento. Raramente, pode ter uma apresentação aguda com evolução rápida para ileus. 0 diagnóstico é confirmado através de exames de imagem [tomografia axial computorizada (TAC) com contraste oral e endovenoso, estudo baritado do trânsito intestinal, ecografia ou ressonância magnética (RMN)]. 0 tratamento inicial, e na ausência de indicação cirúrgica urgente (ex. massa intra- abdominal, aneurisma) é conservador, para alívio sintomático e aumento do índice de massa corporal. Nos doentes com falência desta abordagem justifica-se a intervenção cirúrgica.

0 Síndrome de Nutcracker ${ }^{2}$ é um síndrome raramente descrito. É frequentemente diagnósticado no estudo de hematúria recorrente assintomática. Está associado a alterações anatómica a nível da AMS ou da VRE ou a situações como ptose renal e fibrose retroperitoneal. Manifesta-se com dor localizada ao abdómen e flanco esquerdo com ou sem hematúria macro ou microscópica, pode apresentar-se com o Síndrome de Congestão Pélvico. A ecografia renal com doppler é o método de diagnóstico de eleição. Excepcionalmente pode

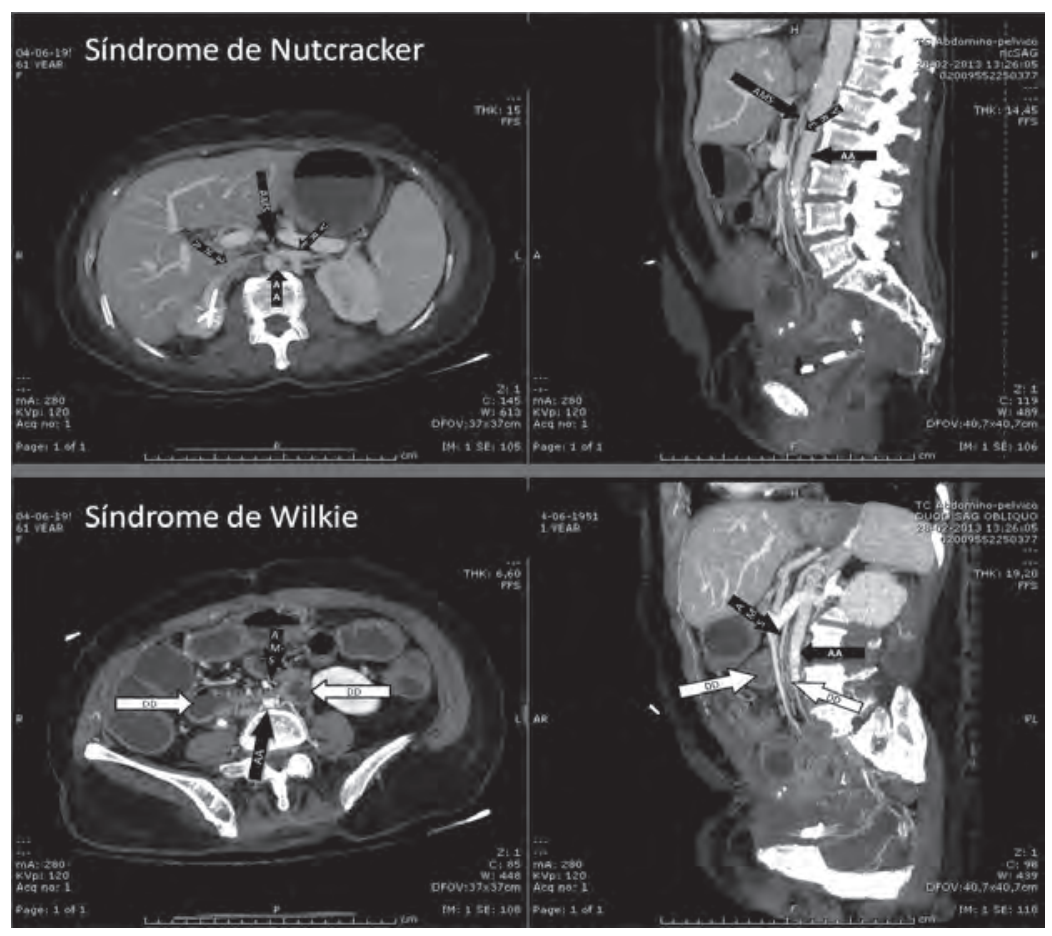

ser necessário recorrer a outros meios complementares como a Angio RMN ou TAC e a angiografia venosa. A terapêutica médica preconiza-se para controlo da dor, da anemia e do Síndrome de Congestão Pélvica. A terapêutica cirúrgica está a ser substituída pela abordagem vascular. Os resultados a curto prazo destas técnicas tem sido satisfatórios, e se assim se mantiverem poderão tornar-se 0 tratamento de primeira linha desta síndrome.

No caso descrito, o desenvolvimento destes síndromes foi secundário à perda do panículo adiposo mesentérico e consequente oclusão intestinal proximal e compressão da veia renal esquerda.

\section{Bibliografía}

1. Welsch T, Büchler MW, Kienle P. Recalling superior mesenteric artery syndrome. Dig Surg. 2007 Jan; 24(3):149-56.

2. Ahmed K, Sampath R, Khan MS. Current trends in the diagnosis and management of renal nutcracker syndrome: a review. Eur J Vasc Endovasc Surg. 2006 Apr; 31(4):410-6.

\section{Diagnóstico: Síndrome de Wilkie e Síndrome de Nutcracker}

Isabel Jesus Pereira ${ }^{1}$, Catarina Tavares ${ }^{2}$

${ }^{1}$ Serviço de Medicina Interna. ${ }^{2}$ Serviço de Imagiologia. Hospital Pedro Hispano. Matosinhos. Portugal

Correspondencia: misabel_.jp@hotmail.com

Como citar este artículo: Jesus Pereira I, Tavares C

Sindrome de Wilkie e Sindrome de Nutcracker. Galicia Clin 2014; 75 (1): 44 Recibido: 15/10/2013; Aceptado: 31/01/2014 